\title{
The Impact of Cultural Capital on Secondary Student's Performance in Brazil
}

\author{
Bernardo Caprara ${ }^{1,2}$ \\ ${ }^{1}$ Department of Social Sciences, Federal University of Fronteira Sul, Brazil \\ ${ }^{2}$ Department of Sociology, Federal University of Rio Grande do Sul, Brazil
}

Copyright $\bigcirc 2016$ by authors, all rights reserved. Authors agree that this article remains permanently open access under the terms of the Creative Commons Attribution License 4.0 International License

\begin{abstract}
The main goal of this study is to verify the effects of cultural capital on students' performance in an official test applied by the Brazilian government, as part of the National Assessment of Basic Education (Saeb). The data set used is from 2003 and involves 52.434 students. The standard test is applied every two years in the fields of mathematics and languages. A questionnaire is applied along with the test in order to measure the student's characteristics as well as their families' profile. The question of this research is: what is the impact of cultural capital on student's performance in the Saeb test? The theoretical approach is based on the work of Pierre Bourdieu. As contributions of Brazilian scholars the study includes the ideas of Nelson Silva and Carlos Hasenbalg and Carlos Ribeiro. The model of study considered the students' grades in the Saeb test as the dependent variable and the cultural capital as the main independent variable. The descriptive analysis was used as well as regression models in order to obtain the effect of the independent variables over the dependent one. The preliminary and main results show that there is significant association between levels of cultural capital and student's performance in the Saeb test. Specifically, there is a significant and positive correlation between parents' education, computer ownership, access to internet and newspaper reading with the performance in the Saeb test.
\end{abstract}

Keywords Cultural Capital, Inequalities, Students' Performance, Sociology of Education

\section{Introduction}

This article aims to verify the impact of external cultural elements to schooling on the performance of Brazilian students in basic education, who participated in the National Assessment of Basic Education (Saeb) in 2003, coordinated by the Ministry of Education (MEC). From Saeb, held every two years by the National Institute for Educational Studies and Research "Anísio Teixeira" (INEP), we took the Prova
Brasil (Brazil's Test, which measures the proficiency of students in certain disciplines) and the application of a questionnaire that contextualizes the respondents' experience.

There are many sociological research and theories that provide arguments in order to reflect on the school environment. A part of them could clarify the relations between social inequalities and students' performance. In this scenario, albeit the different approaches, it is important to highlight the works of Coleman [1], Bourdieu [2], Forquin [3] and Bernstein [4], among others, in the international field. Similarly, in Brazil, for instance, the studies of Silva and Hasenbalg [5], Barbosa [6], Nogueira, Cunha, Viana and Resende [7], Soares and Collares [8], Gamboa and Waltenberg [9] are considered important references.

Until the 1980s and 1990s the scientific researches that considered external components to schooling in shaping students' performance were dominant. New analysis and perspectives came after that period. Educational institutions began to be considered an effective part in the results presented by their students, although the perspective of their social background was not excluded from the process. The school would take the possibilities of reproducing inequalities as well as produce new social situations.

The relationship between families and students as well as family engagement in the journey of the young students and the strategies adopted constituted some of the relevant aspects added to the investigations [10]. Still, the family cultural capital, and the connection of households with the dominant culture, share space with such factors and can portray an edifying aspect in achieving students' good performances.

The idea that crosses this article relates to Bourdieu's [11] theory, as it suggests that the possession and the volume of cultural capital may shape the pathway of the actors in the school field. In short, the hypothesis investigated implies the centrality of the students' cultural capital in the achievement of good or bad school performance in Brazil in early twentieth century. Based on these concepts, on Saeb 2003 data base and on the statistical technique of Multiple Linear 
Regression, this paper allows us to analyze the impact of some variables in the Brazilian educational performance.

\section{The Sociology of Education and Pierre Bourdieu}

The Sociology of Education addresses in different ways the topic of the relationship between inequality and education. Thus, Bernstein [12] helps us to understand the connections of language in different social conditions with school performance. Analyzing the speeches of children originating from working sectors and children from the upper classes, Bernstein introduced what became known as "the two codes theory." For him, there are two kinds of language, two use modalities of language, the "restricted code" and the "elaborated code" which guide the ways of relating to the world.

The idea of "restricted code" allows us to notice a common language interlaced to the life context, usually spoken by children of the working-class families, and too complicated to be disassociated from images of everyday life. On the other hand, the so-called "elaborated code" represents the formal language, which the children of elites share and use since ever. In the set of "elaborated codes", there is less dependence on the actual situations, in the sense that it is a more universalized language framework. Bernstein's argument indicates that social and family structure can model thinking and cognitive styles of problem solving.

The work of researchers from the University of Oxford, Nuffield College, consider the class differences in educational outcomes and in the probability of social mobility as a product of the aggregation of individual actions, governed by a kind of instrumental rationality. Taking as a premise the fact that individuals use their original social position as a reference to their desires and future projects, it is possible to conclude that their choices in the educational environment are guided by the attempt to mitigate the risks of a downward mobility or social disqualification [13].

Individuals would carry different perceptions about the minimum acceptable levels in educational outcomes. The perception of the minimum stage to achieve in school among these individuals is variable, as they seek similar goals facing opportunities and variable difficulties that refer to their position in the class structure. Their choices end up being adaptive strategies on the structure of opportunities and difficulties that may or may not constrain individuals according to their class positions and strategies they adopt to reduce the risk of going to a "lower" position.

The unequal distribution of opportunities in schools would be the result of the aggregation of individual actions and social groups that have unequal amounts and types of resources able to guarantee the social reproduction, generation after generation. Basically, these studies have made efforts to examine the persistence and change in differences of educational opportunities among different social groups. They also want to analyze the ways in which institutional structures and regulations of the educational systems achieve the distribution of educational opportunities.

Just like the studies derived from the Nuffield program, the line of research on social classes and education founded on Pierre Bourdieu's work builds the object of analysis by trying to identify class differences in educational outcomes and the nature and intensity of school investments according to different strategies of social reproduction. However, this tradition distinguishes precisely in the motto attributed to the unequal distribution of capital among individuals and classes. More than that, it defends an emphasis on the inclinations to believe in something and act this or that manner. It is the habitus, the substrate of different class practices).

The school field has a prominent place in Pierre Bourdieu's [14] studies. However, his work is very broad and needs to be thought from some concepts and their intersections. The purpose of this section is to clarify the concepts that we consider central in Bourdieu's theory: social space, capital, habitus, and fields.

The basis for the concept of social space is the idea of difference, separation, agglutinated coexisting positions but also distinct. Bourdieu portrays the modern society using the image of a social space in which the agents are located in different relative positions, according to the distribution of properties among them. These properties are forged as power resources and refer to different forms of capital that can be appropriated by the agents.

In general terms, Bourdieu mentions four types of capital. When it comes to economic capital, he highlights the control of economic resources in a given society, as private ownership of movable and immovable property; the domination of offers of goods; and services and the direction of companies. Social capital represents a set of relationships produced in the course of a path (recognition, authority, prestige, influence, etc.). Symbolic capital, in turn, relates to the ability to impose a particular view of the world, always anchored in a division (them versus us), through a type of legitimate language with the pretension to conforming to "the truth".

Cultural capital comprises a set of resources and competencies that are available and mobilizable when it comes to the dominant culture (or high culture). It is the taste and aesthetic disposition enjoyed by the dominant and translated into a embodied state through habitus (systematic arrangements and schemes of perception). This is the most complicated aspect to be acquired by the dominated, since there is a gap between learning about music or arts and expressing preference and enjoying elements of the dominant culture. "As it is personal, the acquisition work is a work of the 'subject' over himself (let's say 'to cultivate')". The two other cultural capital states are, respectively, the objectified by the possession of cultural objects in domestic environment and the institutionalized by the possession of recognized school titles that appear as a distinctive support of dissimilar groups of agents. 
Types of capital are important resources for agents to fight over symbolic struggles in different fields, and can be monopolized. In certain cases they may be transmitted or converted. In the context of relations between social classes and school, the cultural capital stands out as a key resource for the success of agents in formal education. Cultural capital describes, say Bourdieu [15], the "(...) instruments of appropriation of symbolic goods that a social structure selects as worthy of being desired and possessed". This means that the "naturalness" to deal with "high culture", expressed by the volume of the cultural capital of the agents, tends to increase the chances of students to rise up the satisfactory results in their academic careers.

The agents are not located in the social space having the same "tools" to the familiarity with the pedagogical communication, which is so precious to schooling, or to maximize their educational performance. Considering the positions that agents occupy in the social space and the paths they develop to reach them, keep or develop, agents incorporate ("turn into body") disparate schemes of dispositions to believe in something or act in such a way that consolidates its habitus, driving a mechanism of "choices" that agents do in society. Thus, habitus is a structured structure, as it results from social conditions that refer to a specific class of existence conditions. It is, at the same time, a structuring structure, because it creates a generator principle of multiple practices and limited improvisation.

The habitus characteristics delimit a kind of homogeneity between the practices of agents located in nearby social space positions, which engenders their class practices that do not depend on the agents' intentionality. In addition, the habitus characteristics indicate a pre-reflexive adjustment of the agents' subjective pretensions with the objective probabilities of educational success - a "practical sense" between what is probable, what is possible and what should effectively happen. "The strategies of school investment are a component of social reproduction strategies", said Bertoncelo [16].

According to Bourdieu, the agents are considered agents in the sense that, in the peculiar rhythm of their existence in the fields, they build the habitus, their enduring and permanent dispositions, the playing of the game, the incorporated dispositions that will guide their decision making. It refers to the social structures of human subjectivity initially built in the occurrence of the first social experiences (primary habitus) and later in the adulthood (secondary habitus). It is a unifying principle, which reconstructs the veiled unity in the diversity of established practices in areas analyzed from different logics. The habitus is how social structures are printed on the rationality and the body of the agents through the internalization of externality. A system of durable and transposable dispositions, in which multiple responses to changing situations are given from a limited set of actions and thought schemes.

The fields are relatively autonomous microcosms, intermediate universes in which there would be the agents and institutions that "produce, reproduce or disseminate arts, literature or science" [17]. In other words, the fields are social worlds that correspond to more or less specific social laws. All fields are fields of force and dispute, and the position taken by each agent in the distribution structure of the specific capital of each field will conduct their possibilities of action. In theory, inside the school field, cultural capital of students can condition their careers in a world of systematized knowledge, making those who already came from a favorable situation since birth keep their positions in the course of the events.

\section{Methodology}

In order to measure the influence of cultural capital of student's in their school performance, we opted for a quantitative methodology. For this purpose, we used the database of National Assessment of Basic Education (Saeb) of 2003, produced by INEP, an organ of MEC (Education Ministry).

The analysis is based on the accomplishment of the use of Multiple Linear Regression, in which the dependent variable is the students' proficiency in mathematics and Portuguese tests. The independent variables are intended to cover the cultural capital, the socioeconomic conditions, the involvement of families and the school pedagogical practices, as well as aspects such as region of the country, sponsor of the school network, sex and skin color of the students.

\subsection{Database}

The Saeb appeared in 1990 with the purpose of expressing an amplified and permanent diagnosis of Brazilian education. Since 1995, the ratings began to take place every two years and the methodology has become standard, the Item Response Theory (IRT). The advantage of this methodological tool is to allow the temporal comparison of Saeb results. In summary, the IRT proposes models of understanding the characteristics of individuals that are not observable in a direct way [18].

The Saeb database that is going to be analyzed in this research, dates from 2003 and was taken from the Social Information Consortium (CIS) of the University of São Paulo (USP). It contains the variables of the contextual questionnaire of the student and their performance in tests. We chose this database as it expresses the Brazilian educational reality in the early years of the twenty-first century, marking a parameter and guiding future comparative studies. In the database there are responses from 52,484 students from public (state, municipal and federal) and private schools, from urban and rural areas. All of the students are in the third year of high school (the last year of basic education). Skills and abilities expected for math and Portuguese language were measured, encoded into descriptors and income levels.

The sample size is based on a synthesis that includes all the students enrolled in 2003 in constant urban schools from 
the School Census 2002 in one of the three series of interest, excluding students in multigrade classes and acceleration programs. The sampling plan brings together two phases. At first, there is the choice of schools defined as the parts of the schools that correspond to all classes and students of each series considered in the assessment. In the second stage, it occurs a class selection within the educational institutions chosen in the first stage. In each selected class, all students take the tests (in different subjects) and respond to quizzes. Roughly speaking, there are three divisions: the first is the selection of schools, the second, the selection of classes, and the third corresponds to the selection - within the group - of a group of students to participate in the assessment of each discipline.

\subsection{The Variables}

Table 01 presents the variables chosen for this study. Also, it indicates the values for each variable. The educational performance is measured by Saeb 2003 note, which is a point scale from 0 to 500 . This is the dependent variable. The others are the independent variables. They were operationalized mainly because of the current use found in the literature, but in fact, it is a choice that intends to create a discussion that goes beyond the purposes of this study.

Table 1. The variables

\begin{tabular}{|c|c|c|}
\hline Dependent variable & Indicators & Measures Saeb 2003 test \\
\hline Saeb 2003 Proficiency & Quantitative indicator & Points in math and Portuguese \\
\hline Independent variables & Indicators & Measures Saeb 2003 test \\
\hline \multirow{5}{*}{ Cultural capital } & Mother's education & Did your mother finish college? $($ No $=0$, Yes $=1)$ \\
\hline & Father's education & Did your father finish college? $(\mathrm{No}=0, \mathrm{Yes}=1)$ \\
\hline & Cultural habits & Do you watch movies in the theater? $(\mathrm{No}=0, \mathrm{Yes}=1)$ \\
\hline & Access to cultural goods & $\begin{array}{l}\text { Do you have many books at home? (several shelves) (No } \\
=0, Y e s=1)\end{array}$ \\
\hline & Access to cultural goods & $\begin{array}{l}\text { Do you have few books at home? (one shelve) }(\mathrm{No}=0, \\
\text { Yes = } 1 \text { ) }\end{array}$ \\
\hline Independent variables & Indicators & Measures Saeb 2003 test \\
\hline \multirow{4}{*}{ Social class } & Ownership of durable goods & $\begin{array}{l}\text { Is there a computer with internet at home? }(\mathrm{No}=0, \text { Yes }= \\
1)\end{array}$ \\
\hline & Ownership of durable goods & Do you have a freezer at home? $(\mathrm{No}=0, \mathrm{Yes}=1)$ \\
\hline & Household chores & Is there any maid working at your house? $(\mathrm{No}=0, \mathrm{Yes}=1)$ \\
\hline & $\begin{array}{c}\text { Early insertion in the labor } \\
\text { market }\end{array}$ & $\begin{array}{l}\text { Do you work outside home during school days? }(\mathrm{No}=0 \text {, } \\
\qquad \text { Yes = 1) }\end{array}$ \\
\hline Familiar involvement & Monitoring of education & His parents follow your school life? $(\mathrm{No}=0, \mathrm{Yes}=1)$ \\
\hline Sex (dichotomous) & Own identification & $\begin{array}{c}\text { Male }=0 \\
\text { Female }=1 \\
\end{array}$ \\
\hline \multirow{4}{*}{ Skin color (reference = white) } & Own identification, black & $\begin{aligned} \text { Black } & =1 \\
\text { Others } & =0\end{aligned}$ \\
\hline & Own identification, "pardo" & $\begin{array}{l}\text { Pardo }=1 \\
\text { Others }=0\end{array}$ \\
\hline & Own identification, yellow & $\begin{array}{l}\text { Yellow }=1 \\
\text { Others }=0\end{array}$ \\
\hline & $\begin{array}{c}\text { Own identification, } \\
\text { indigenous }\end{array}$ & $\begin{array}{c}\text { Indigenous }=1 \\
\text { Others }=0\end{array}$ \\
\hline \multirow{4}{*}{ Country region (reference $=$ Southeast $)$} & North & $\begin{array}{l}\text { North }=1 \\
\text { Others }=0\end{array}$ \\
\hline & Northeast & $\begin{array}{l}\text { Northeast }=1 \\
\text { Others }=0\end{array}$ \\
\hline & Midwest & $\begin{array}{l}\text { Midwest }=1 \\
\text { Others }=0\end{array}$ \\
\hline & South & $\begin{aligned} \text { South } & =1 \\
\text { Others } & =0\end{aligned}$ \\
\hline \multirow{3}{*}{$\begin{array}{l}\text { Schools maintainer network } \\
\text { (reference = private schools) }\end{array}$} & State school & $\begin{array}{c}\text { State school }=1 \\
\text { Others }=0\end{array}$ \\
\hline & Municipal school & $\begin{array}{l}\text { Municipal school }=1 \\
\text { Others }=0\end{array}$ \\
\hline & Federal school & $\begin{array}{c}\text { Federal school }=1 \\
\text { Others }=0\end{array}$ \\
\hline Teacher/Pedagogy & Teacher involvement & $\begin{array}{l}\text { Is your teacher always available? } \\
\quad(\mathrm{No}=0, \mathrm{Yes}=1)\end{array}$ \\
\hline
\end{tabular}


The cultural capital consists of four variables that try to cover different dimensions: mother's education, cultural habits and access to cultural goods. Mother's education can help operationalize the idea that the student incorporates, through habitus, the fruits of the family's academic success. In addition, it can also indicate an approximation to the institutionalized dimension of cultural capital. Cultural habits can also express the incorporation of these different cultural "dispositions". And the access to cultural goods expresses an objective dimension of cultural capital.

Socioeconomic conditions can cover the access to durable goods by the family and the student, and also the possibility of delegating the household chores by hiring a maid and the early integration of students into the job market. Family involvement is related to the parents monitoring of young peoples' school life. Pedagogical practices are explored in a variable about the teacher/student relationship.

\section{Analysis of Empirical Results: Cultural Capital and Educational Performance in Brazil}

We conducted a Multiple Linear Regression containing the two subjects: mathematics and Portuguese, in addition to all the variables described in all regions of the country, which we will call "complete regression". Then we conducted a regression with all variables for each region (having subtracted the regional variables) in order to realize the differences in the impact of cultural capital on each region. Finally, we conducted a regression containing all the variables for each subject and thus noticed the different influences of the variables in the results of mathematics and Portuguese language separately. In the text, it was presented only the table of coefficients of complete regression, endowed with all variables, all regions of the country and both assessed disciplines [19].

\subsection{Complete Regression}

This study aims to measure the impact of cultural capital of Brazilian students in their educational performance. For this purpose, we adopted the quantitative methodology based on secondary data. We opted to use the Saeb 2003 database, which provides us with information about the educational reality in Brazil in the early twenty-first century, and allows us to make comparisons for future studies.

In Saeb 2003 database, the dependent variable is the students' grades on math and Portuguese tests which is a scale of 0 to 500. The independent variables which operationalize the concept of cultural capital and other aspects relevant to the phenomenon in question are arranged in Table 1. We performed a Multiple Linear Regression and obtained the following results, detailed in Table 2 .

Table 2. Complete Regression

\begin{tabular}{|c|c|c|c|c|c|c|c|c|}
\hline & \multirow{2}{*}{ Model } & \multicolumn{2}{|c|}{ Not standardized coefficients } & \multirow{2}{*}{$\frac{\text { Standardized coefficients }}{\text { Beta }}$} & \multirow{2}{*}{$\mathrm{t}$} & \multirow{2}{*}{ Sig. } & \multicolumn{2}{|c|}{ Collinearity statistics } \\
\hline & & $\mathrm{B}$ & Standard model & & & & Tolerance & VIF \\
\hline & (Constant) & 310,361 & 1,228 & & 252,821 &, 000 & & \\
\hline & Did your mother finish college? & 8,416 & ,690 &, 056 & 12,199 & 000 & ,688 & 1,453 \\
\hline & Did your father finish college? & 11,628 & ,711 & 075 & 16,354 & 000 & 676 & 1,480 \\
\hline & Do you go to the movies? & 5,235 &, 561 & 039 & 9,336 & 000 & 823 & 1,215 \\
\hline & $\begin{array}{l}\text { Many books at home (several } \\
\text { shelves) }\end{array}$ & 2,512 & ,738 &, 014 & 3,405 &, 001 & ,794 & 1,259 \\
\hline & Few books at home (one shelf) & $-5,578$ & ,516 &,- 046 & $-10,819$ & 000 & ,804 & 1,244 \\
\hline & Do you have a freezer at home? & 2,114 & 506 & 017 & 4,181 & 000 & 827 & 1,209 \\
\hline & $\begin{array}{c}\text { Is there any maid working in your } \\
\text { house? }\end{array}$ & 1,221 &, 588 &, 010 & 2,078 &, 038 & ,673 & 1,485 \\
\hline & $\begin{array}{c}\text { Do you work outside home on } \\
\text { school days? }\end{array}$ & $-17,146$ &, 536 &,- 132 & $-31,984$ &, 000 &, 848 & 1,180 \\
\hline & $\begin{array}{c}\text { Is there a computer with internet in } \\
\text { your house? }\end{array}$ & 13,877 & ,627 &, 111 & 22,147 &, 000 &, 573 & 1,744 \\
\hline 1 & \begin{tabular}{|c|}
$\begin{array}{c}\text { Do your parents follow your } \\
\text { school life? }\end{array}$ \\
\end{tabular} &,- 926 &, 567 &,- 006 & $-1,633$ & ,103 & ,973 & 1,028 \\
\hline & Skin color - dark & $-9,447$ & 1,004 &,- 038 & $-9,407$ & 000 & 900 & 1,111 \\
\hline & Skin color - Pardo & $-2,666$ &, 537 &,- 021 & $-4,962$ & 000 & ,785 & 1,274 \\
\hline & Skin color - Indigenous & $-14,513$ & 1,671 &,- 034 & $-8,683$ & ,000 & ,964 & 1,038 \\
\hline & Skin color - Yellow & $-2,830$ & 1,138 &,- 010 & $-2,487$ &, 013 & ,945 & 1,058 \\
\hline & Sex & $-4,651$ & 475 &,- 038 & $-9,793$ & 000 & 952 & 1,051 \\
\hline & North & $-17,263$ &, 855 &,- 092 & $-20,188$ &, 000 & ,688 & 1,453 \\
\hline & Northeast & $-12,980$ & ,655 &,- 103 & $-19,815$ &, 000 &, 535 & 1,870 \\
\hline & Midwest & $-4,142$ &, 813 &,- 023 & $-5,092$ &, 000 & ,706 & 1,416 \\
\hline & South & 3,878 &, 750 &, 024 & 5,173 &, 000 & ,648 & 1,544 \\
\hline & Federal School & 24,134 & 1,748 & 053 & 13,804 &, 000 & 966 & 1,035 \\
\hline & Municipal School & $-37,393$ & 2,144 &,- 068 & $-17,443$ &, 000 & ,947 & 1,056 \\
\hline & State School & $-34,538$ & ,609 &,- 284 & $-56,732$ & 000 & 571 & 1,752 \\
\hline & Is your teacher always available? & 5,518 &, 655 &, 032 & 8,426 &, 000 & ,991 & 1,009 \\
\hline
\end{tabular}

Source: Saeb 2003. 
The totality of the model of analysis proposed here (the "complete regression") explains almost $35 \%\left(\mathrm{r}^{2}=0,348\right)$ of the variation of Brazilian students' performance, measured by the note on the scale of Saeb (0-500). All variables in this section were statistically significant at the level of $95 \%$ $(\mathrm{p}<0,05)$.

From the point of view of the variables that express students' cultural capital, we can verify a strong impact on their performances. Some of the variables with the greatest positive impact on the students' score are indeed the variables of cultural capital: mother and father's education. In this case, each student whose mother has completed higher education tends to gain, on average, 8.4 more points in his grade on Saeb. Each student who has a father with a university degree tends to have, on average, 11.6 more points. This is an important result because it shows that the generations of mothers and fathers with higher education can influence their children in their academic results. The students, who go to the cinema, which is a cultural habit, tend to have, on average, 5.2 more points than others. It is also interesting to notice that students who have many books at home tend to have, on average, 2.1 more points, and those who have few books, by contrast, tend to have, on average, 5.5 points less than others. The four variables that express cultural capital indicate a strong impact on Brazilian educational performance in the early twenty-first century, which, to some extent, confirms the expectations of this research.

Socioeconomic conditions show great importance in the relations we have examined in this investigation. Three variables deserve a closer attention. Each student who works outside home on school days tends to lose, on average, 17.1 points in the assessment. This means a very strong and negative impact, which gives evidence of the fact that economic issues are located in the first levels of analysis about school failure or success. Having refrigerator with freezer and computer with internet connection at home, distinctive features of Brazil in 2003, is also an impact on the results of the young people. Having a computer at home with internet tends, on average, to increase the grade in 13.8 points. It is one of the most crucial aspects of the model that was used. The social origin still conforms the results of students [20].

Inequalities related to skin color persist in Brazilian education [21]. We could see that the data shows that black people have a tendency to lose, on average, 9.4 points on Saeb test if compared to white people. Indigenous individuals have an even greater negative tendency in the same comparison: they tend to have, on average, 14.5 less points than black people. Pardos [22] also tend to have, on average, 2.6 less points than white people. There is then a clear element associated with the skin color of the students, which portrays more difficulties for black people, pardos and indigenous succeeding in school.

There are differences when considering the regions of Brazil. We chose, as a reference, the southeast region, having the focus on their demographic, economic and cultural importance. Cities like São Paulo and Rio de Janeiro concentrate millions of people and represent the dynamics of our urban life. Each student who lives in the North tends to lose, on average, 17.2 points in mathematics and Portuguese, in relation to the Southeast. In the Northeast, the negative tendency is of 12.9 points. In the Midwest, students tend to lose, on average, 4.1 points on the test. In the South, we have the only positive trend. Each of the students from the South tends to gain, on average, 3.8 more points compared to the Southeast. The regional inequalities appeared to be related to educational performance.

We must talk about the differences between the schools maintainer networks. If we do not have enough data to go more deeply in pedagogical questions or teaching characteristics, we can reflect on the results of different sponsors. It was used, as a reference, the private schools based on the "Brazilian common sense" that says they are qualified schools. State funded schools show that each student tends to lose, on average, 34.5 points on Saeb, in relation to private schools. Municipal funded schools, in turn, have a tendency to a greater loss: 37.3 [23]. The most interesting is the result of Federal schools. Compared to private schools, each Federal school student tends to gain, on average, 24.1 more points in the Saeb scale in mathematics and Portuguese. This finding shows the quality of federal schools and the importance of the network maintained by the Union to make possible a higher educational performance and a promotion of a better education quality.

Finally, it is worth emphasizing two missing topics. Being a woman means having a tendency to lose, on average, 4.6 points in Saeb test. This indicates the presence of a gender inequality in the school performance. This scenario shows the need for further studies to understand the dynamics of these inequalities.

When the teacher is always available in the classroom, students tend to have, on average, 5.5 more points. Another aspect that requires further research is the result of the variable that expresses the family's involvement. The variables tested through exploratory models and the variable that was best adapted to the models did not achieve statistical significance. This creates a controversy in relation to studies that claim family involvement to achieving academic success [24].

In summary, the results of the "complete regression" show the strength of cultural capital when it comes to conforming the educational performance of students in the last year of Brazilian high school, in the rush of the twenty-first century. Economic capital or social class also generated strong impacts on students' grades, as well as being white and male. Also studying at Federal and private schools, and residing in the South and Southeast. In fact, we have an image of the power of the main inequalities of our century and their effects on school performance of our youth.

\subsection{Regressions by Region and Discipline}

After acknowledging an overview of the variables that 
impact in a more decisively way the educational performance measured by Saeb 2003, we conducted seven other regressions in order to apprehend the internal results to each region and each discipline (math and Portuguese language). Considering the scope of this article, we will not present the statistics of those regressions. We will talk about their results, though.

We will start from the regions of Brazil. In the South, our model explains $26 \%$ of variations in the scores of the students assessed. All results of the cultural capital had statistical significance at $95 \%(\mathrm{p}<0,05)$. Mother and father's schooling variables must be highlighted. If students have father and mother with a university degree, they tend to have, on average, 9,7 and 7,2 more points, respectively. From the socioeconomic class perspective, working out on school days means the tendency to lose, on average, 13.4 points. When it comes to skin color, sex, the maintainer network and teacher availability, the results are similar to the "complete regression" which indicates that inequalities are associated to those factors in shaping educational performance. In particular, black people tend to lose, on average, 17.4 points in the test, which calls our attention to this racial inequality element in the South.

In the Southeast, the model explains almost $34 \%$ of the variation of the grades. Having parents with higher education causes the tendency to gain, on average, 9.5 (mother) and 9.8 (father) more points than the others. Again, culture capital variables were all statistically significant up to $95 \%$ (p < $0,05)$. Regarding the socioeconomic status, working outside on school days tends to lead students to lose, on average, 20.4 points in the tests, which shows that early insertion in the job market is a relevant factor to create difficulties for the school success in the Southeast. Black people, pardos and indigenous continue losing if compared to white people. Federal schools continue presenting an increase in the grades. State and Municipal ones keep causing grades to decrease, in relation to private schools.

The Midwest and North showed that our model explains $32 \%$ and $28 \%$ of the variation of the grades of students that were respondent to Saeb in each of the regions. In these locations, many variables were not statistically significant at the expected level. Those that were relevant followed the rhythm of the "complete regression" results and so far, regional regressions gave descriptions with no major changes. As in all other analyzes, cultural capital was relevant to the educational performance of young people of the third year (the final year of basic school) investigated by Saeb 2003.

In the Northeast, we can see the inequalities manifesting strongly, no matter if they are cultural or economic. Our model explained $33 \%$ of the variation of the grades in that region. To every student who has a father with complete college degree, the tendency is to gain, on average, 13.5 more points in Saeb test. To every student who works outside home on school days, the trend is to lose, on average, 18.9 points. Having a computer with Internet connection at home tends to increase the grade, on average, in 16.4 points. In relation to white people, indigenous tend to lose more, as well as black people, although it is a smaller volume. Women tend to lose, on average, 8.8 points in the Saeb scale, which shows that, in the Northeast, being a woman is a central factor for the difficulties in educational performance.

Least but not last we still need to analyze the results for the regressions that differentiated math and Portuguese. Concerning mathematics performance, our model achieved the highest explanatory power $-41 \%$ of the grades variation of all regressions that were done. Cultural capital proved to be important when related to parents' education variables (tendency to gain, on average, 10.4 points if the mother has a college degree and 13.5 if the parent has it). Working outside home on school days makes life hard for students of mathematics, because they tend to lose, on average, 17.2 points in math test. Having a computer with internet connection at home, on the other hand, helps the students because each one has, on average, 15.8 more points. Black people and indigenous indicate high negative trend as well as women in mathematics, which makes us reflect on the issue of gender and performance connected to numbers in school. Compared to the Southeast, students from North, Northeast and Midwest lose points.

The results for the isolated discipline of Portuguese are somewhat different. Our model explained $31 \%$ of variation in proficiencies in Portuguese. Cultural capital variables were all relevant to educational performance, unlike what occurred in the discipline of mathematics. The social class variables followed the pace shown in the previous regressions and also, the effects of skin color, school system and region of the country. However, it is worth noting the huge difference found for the first time in this study, with respect to gender. So far, being a woman means having more difficulties in showing good school performance within the general framework and mathematics. In Portuguese, the relationship is reversed, and women tend to gain, on average, 8.1 more points the Saeb scale of Portuguese assessment. This is a significant increase and can gives us support for further research, compromised to understand the reasons that caused greater female difficulties in mathematics and more facility in Portuguese.

\section{Discussion}

Our results relate to other studies that investigate the impact of cultural elements and social class in formal education. The article by Gamboa and Waltenberg [25] which is a research that uses information produced by PISA with evidence of 2006 and 2009, portrays part of the inequalities of opportunity in the educational development of Latin America. Through a comparative approach between the six countries in the continent (Argentina, Brazil, Chile, Colombia, Mexico and Uruguay), the researchers on Inequality and Development Studies Center (CEDE) from the Federal Fluminense University (UFF) measured the differences in opportunities using the following variables: 
gender, type of school (public or private), family education and the combination of them all. The results show that parents' education and type of school (especially in Argentina and Brazil) are key factors in relations of unequal opportunities that affect education.

Saeb 2003 data was important to the work of Soares and Collares. They tried to identify the links between family resources and cognitive performance of children and young students in primary education. Their findings show "(...) a complex portray of the relationship between family characteristics, school type and student performance" [26]. Also, it is worth highlighting that their interpretations do not look upon the effects of family components as inferior to the school ones, which suggests that the effects arising from the influence of the families can be dominant in school results.

Using a sample of people between six and 19 years of age, Silva [27] studied the effects of social origins over three school transitions. The operationalization of social origin tried to characterize the concept of cultural capital, engendered by Bourdieu, indicating a variable on the education of the individual seen as the householder. The characterization of the economic capital indicates the family variable income. There was also the characterization of the idea of social capital, considering the variable that determines whether the householder was a woman and the number of children in the family. Evidence showed a decrease in the influence of the elements that indicate the students' social origin on the first school transition, especially in the 1990s. However, regarding to the other transitions analyzed, the effects of social origins were stabilized in the time series, demonstrated by the variable of the householder education. Such effects have grown, even if we observe variables relevant to the sex of the householder and the family's living area.

Finally, Ribeiro argues that no development of a robust educational policy will succeed in Brazil, if a massive focus on reducing social inequalities does not happen. "The analysis shows that even when we take into account the type of school, the socioeconomic inequalities of opportunity remain" [28]. In other words, for Brazilian educational system to have a decent quality of what is expected in the nation, it is essential to make improvements in the quality of education and especially the living conditions of families.

\section{Final Considerations}

Having the comprehension of what makes some individuals and social classes get better or a worse result in schooling is a complex task. It requires the confluence of qualitative and quantitative empirical researches, theoretically founded and in constant dialogue with the latest findings.

This article verified the importance of cultural capital, concept edified by Pierre Bourdieu [29], in obtaining academic achievement in basic education of 52,434
Brazilian students in their final year of high school at the beginning of the twenty-first century. Having the Saeb 2003 database as a reference, we conducted a Multiple Linear Regression, with proficiency in mathematics and Portuguese as the dependent variable and all other independent ones listed in Table 1. Then, we conducted seven other regressions aiming to comprehend the regional features and differences between math and Portuguese language. The aspects we considered in our model were basically the following: cultural capital, socioeconomic status, family involvement, region of the country, maintainer network, sex, skin color and a pedagogical variable.

Our findings demonstrated that cultural capital of students remains as a central element in shaping the educational performance of young Brazilians. We can say that young people who tend to get high school grades carry cultural objects and have cultural habits and a family with high education. They are situated in a social class that does not need to work during class period, may delegate household chores to an employee and have access to durable goods that are relatively scarce.

The aspects that this tradition of studies - about class inequalities and their relation to formal education - leave still open, concern the scrutiny of social conditions of genesis and transmission of basic provisions for a qualitative inclusion in the logic of schools. They also fail since they are not able to advance in the investigation of the processes of cultural capital formation in modern capitalist societies which dominates mass culture.

However, the immense variety of circumstances linked to the school environment can never be represented in its totality, no matter how strong the intensity, dedication and talent of the investigator are. Thus, this article shows that the impact of cultural capital in the basic school performance is most likely to be high in Brazil. The findings, derived from the applied analysis model, can give some support to Bourdieu's theory from the beginning of this century.

\section{REFERENCES}

[1] James Coleman. Social capital in the creation of human capital, Education Culture Economy Society, Oxford University Press, Oxford, 1997.

[2] Pierre Bourdieu. Escritos de Educação, Vozes, Petrópolis-RJ, 2007.

[3] Jean Claude Forquin. Sociologia da Educação: Dez anos de pesquisa, Vozes, Petrópolis-RJ, 1995.

[4] Basil Bernstein. Estrutura social, linguagem e aprendizagem. In: PATTO, Maria Helena Souza. Introdução à Psicologia Escolar, Casa do Psicólogo, São Paulo, 1997, pp. 145-169.

[5] Nelson do Valle Silva and Carlos Hasenbalg. Tendências da Desigualdade Educacional no Brasil, Revista Dados, vol. 43, n. 3, 2000, pp. 423-445. 
[6] Maria Ligia de Oliveira Barbosa. Desigualdade e desempenho: Uma Introdução à Sociologia da Escola Brasileira, Argvmentvm, Belo Horizonte, 2009.

[7] Cláudio Marques Nogueira, Maria Amália de Almeida Cunha, Maria José Braga Viana, Tânia de Freitas Resende. A influência da família no desempenho escolar: estudo de dados da geração escolar 2005, Revista Contemporânea de Educação (UFRJ), Rio de Janeiro, vol. 4, n. 8, 2009.

[8] José Francisco Soares and Ana Collares. Recursos familiares e o desempenho cognitivo dos alunos do ensino básico brasileiro. Revista Dados, Rio de Janeiro, vol. 49, n. 3, 2006, pp. 615-650.

[9] Luis Gamboa and Fábio Waltenberg. Inequality of Opportunity in Educational Achievement in Latin America: Evidence from PISA 2006-2009, CEDE - Centro de Estudos sobre Desigualdade e Desenvolvimento, Texto para discussão, n. 49 , julho 2011.

[10] Pierre Bourdieu. Razões Práticas: Sobre a teoria da ação, Papirus, Campinas-SP, 1996.

[11] Pierre Bourdieu. Coisas Ditas, Brasiliense, São Paulo, 1990.

[12] Basil Bernstein. Estrutura social, linguagem e aprendizagem. In: PATTO, Maria Helena Souza. Introdução à Psicologia Escolar, Casa do Psicólogo, São Paulo, 1997, pp. 145-169.

[13] Edison Bertoncelo. Classes sociais, cultura e educação, Revista Novos Estudos, CEBRAP, São Paulo, 104, 2016.

[14] Pierre Bourdieu. A Distinção, Zouk, Porto Alegre, 2008.

[15] Pierre Bourdieu. Os Usos Sociais da Ciência, UNESP, São Paulo, 2004.

[16] Edison Bertoncelo. Classes sociais, cultura e educação, Revista Novos Estudos, CEBRAP, São Paulo, 104, 2016.

[17] Pierre Bourdieu. A Economia das Trocas Simbólicas, Perspectiva, São Paulo, 2011.

[18] Dalton Andrade, Heliton Tavares and Raquel Valle. Teoria da Resposta ao Item: Conceitos e Aplicações, SINAPE, São Paulo, 2000.

[19] The other tables with other factors, as well as the access to the complete database, are available at the website: http://www.sociologiapopular.com/p/caprarabernardo.html.
[20] Carlos Antonio Costa Ribeiro. Desigualdade de oportunidades e resultados educacionais no Brasil, Revista Dados, vol. 54, n. 1, Rio de Janeiro, 2011.

[21] José Francisco Soares and Maria Teresa G. Alves. Relações raciais e desempenho escolar: as evidências do sistema da avaliação do ensino básico - SAEB, ANPOCS - XXVI Encontro Anual, Caxambu, MG, 2002.

[22] In Brazil, pardo is a race/skin color category used by the Brazilian Institute of Geography and Statistics (IBGE) in national censuses, with historic roots in the colonial period. The term "pardo" is more commonly used to refer to mixed-race Brazilians, individuals with varied racial ancestries.

[23] In Brazil, municipal schools correspond, most times, to primary school. Our data corresponds to students of the third year of high school who are about to finish basic education. Perhaps the existence of few local municipal schools that meet high school can influence these results

[24] Maria Alice Nogueira. A Categoria "Família" na Pesquisa em Sociologia da Educação: Notas Preliminares Sobre um Processo de Desenvolvimento, Revista Inter-Legere, n. 9, 2011.

[25] Luis Gamboa and Fábio Waltenberg. Inequality of Opportunity in Educational Achievement in Latin America: Evidence from PISA 2006-2009, CEDE - Centro de Estudos sobre Desigualdade e Desenvolvimento, Texto para discussão, n. 49, julho 2011 .

[26] José Francisco Soares and Ana Collares. Recursos familiares e o desempenho cognitivo dos alunos do ensino básico brasileiro. Revista Dados, Rio de Janeiro, vol. 49, n. 3, 2006, pp. 615-650.

[27] Nelson do Valle Silva. Expansão Escolar e Estratificação Educacional no Brasil. In: Nelson do Valle Silva e Carlos Hasenbalg. Origens e Destinos: Desigualdades Sociais ao Longo do Ciclo de Vida, Rio de Janeiro: Topbooks, 2003.

[28] Carlos Antonio Costa Ribeiro. Desigualdade de oportunidades e resultados educacionais no Brasil, Revista Dados, vol. 54, n. 1, Rio de Janeiro, 2011.

[29] Pierre Bourdieu. A Distinção, Zouk, Porto Alegre, 2008; Pierre Bourdieu. A Reprodução, F. Alves, Rio de Janeiro, 1982. 